\title{
SYNTHESIS AND CRYSTAL STRUCTURE OF A \\ TETRANUCLEAR MIXED-METAL ALKYLIDENE COMPLEX CpWOs $3(\mathrm{CO}),(\mu-\mathrm{O})(\mu-\mathrm{H})(\mu-\mathrm{CHTol})$
}

\author{
SHIE-MING PENG* $†$ and GENE-HSIANG LEE \\ Department of Chemistry, National Taiwan University, Taipei 10764, Taiwan, R.O.C. \\ and \\ YUN CHI* \\ Department of Chemistry, National Tsing Hua University, Hsinchu 30043, Taiwan, R.O.C.
}

(Received 21 November 1989 ; accepted 27 February 1990)

\begin{abstract}
The solid-state structure of a tetranuclear mixed-metal cluster $\mathrm{CpWOs}_{3}(\mathrm{CO})_{9}(\mu-$ $\mathrm{O})(\mu-\mathrm{H})(\mu-\mathrm{CHTol})(2)$ which possesses a bridging hydride, a bridging oxo and a bridging tolylalkylidene ligand is presented. Complex 2 crystallizes in the triclinic space group $P \mathrm{I}$, with $a=9.763(5), \quad b=10.759(4), \quad c=13.336(3) \quad \AA, \quad \alpha=88.00(3), \quad \beta=108.56(3)$, $\gamma=100.44(3)^{\circ}, Z=2 ; 3463$ observed reflections with $I>3 \sigma(I)$ were used in the refinement. The $R$ values converged to $R_{\mathrm{F}}=0.057, R_{\mathrm{w}}=0.058$.
\end{abstract}

The reactivity of mixed-metal clusters has been of interest for many years. ${ }^{1}$ Research in this area is stimulated by a belief that the combination of metals having very different chemical properties within one compound may induce unique chemical transformations. In seeking to develop a systematic way to prepare the mixed-metal clusters of higher nuclearity, Stone and co-workers have used $\mathrm{Cp}(\mathrm{CO})_{2} \mathrm{~W} \equiv \mathrm{CR}$ as a building block to prepare many mixed-metal clusters containing a bridging alkylidyne fragment. ${ }^{2}$ As the number of the mixedmetal alkylidyne clusters has increased dramatically in the past few years, there is increasing interest in examining the chemistry of the alkylidyne clusters because of the possible roles of the alkylidynes as reaction intermediates in, and/or models of various catalytic processes. ${ }^{3}$ In the present study we have explored the hydrogenation of a tetrahedral mixedmetal alkylidyne complex $\mathrm{CpWOs}_{3}(\mathrm{CO})_{9}\left(\mu_{3^{-}}\right.$ $\mathrm{CTol})_{2}(\mu-\mathrm{H})(\mathbf{1})^{4}$ which produces an alkylidene complex CpWOs ${ }_{3}(\mathrm{CO})_{9}(\mu-\mathrm{O})(\mu-\mathrm{H})(\mu-\mathrm{CHTol})(2)$ in

* Authors to whom correspondence should be addressed.

$\dagger$ To whom inquiries concerning the $X$-ray crystallographic work should be addressed. low yield (Scheme 1). The single-crystal X-ray diffraction study on complex 2 suggests that its gross geometry and ligand configuration are complementary to those of the related, structurally characterized $\mathrm{WOs}_{3}$ clusters $\mathrm{CpWO}_{3}(\mathrm{CO})_{9}(\mu-\mathrm{O})(\mu-$ $\mathrm{H})\left(\mu-\mathrm{CHCH}_{2} \mathrm{Tol}\right)(3)^{5}$ and $\mathrm{CpWO}_{3}(\mathrm{CO})_{9}(\mu-\mathrm{O})(\mu-$ $\mathrm{Cl})\left(\mu-\mathrm{CHCH}_{2} \mathrm{Tol}\right)(4)^{6}$ (Scheme 2$)$.

\section{RESULTS AND DISCUSSION}

Hydrogenation of complex 1 in refluxing xylenes solution (1 atm, $6 \mathrm{~h})$ produced an orange-brown solution. The solvent was removed in vacuo and the product purified by thin-layer chromatography (TLC), giving an orange product in low yield. The mass spectrum indicates a parent ion at $m / z$ 1198, corresponding to a composition $\mathrm{C}_{22} \mathrm{H}_{14} \mathrm{O}_{10} \mathrm{Os}_{3} \mathrm{~W}$. The ${ }^{13} \mathrm{C}$ NMR spectrum $\left(\mathrm{CDCl}_{3}, 100.6 \mathrm{MHz}, 213\right.$ K) exhibits nine Os-CO signals at $\delta 194.5,184.4$, $181.4,180.9,176.4,173.2,169.9,169.7,169.1$ and the ' $\mathrm{H}$ NMR spectrum $\left(\mathrm{CDCl}_{3}, 400 \mathrm{MHz}, 294 \mathrm{~K}\right)$ shows two singlets at $\delta 5.52$ and -18.05 , in addition to signals corresponding to one $\mathrm{Cp}$ ligand and one tolyl fragment. The IR spectrum $\left(\mathrm{C}_{6} \mathrm{H}_{12}\right)$ in the carbonyl region shows absorption bands at 2090(s), 2965(vs), 2028(vs), 2020(vs), 2014(s), 2007(m), 


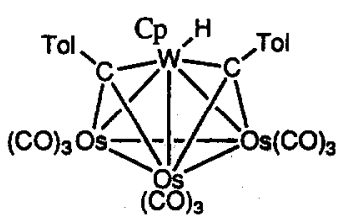

(1)

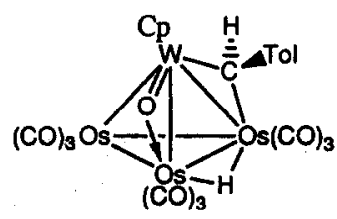

(2)

Scheme 1.

1991(w), 1958(w), $1940(\mathrm{~m}) \mathrm{cm}^{-1}$, indicating that the molecule is analogous to the recently reported dioxo cluster $\mathrm{CpWOs}_{3}(\mathrm{CO})_{9}(\mu-\mathrm{O})_{2}(\mu-\mathrm{H})^{7}$ Based on these spectroscopic data, a formulation $\mathrm{CpWOs}_{3}$ $(\mathrm{CO})_{9}(\mu-\mathrm{O})(\mu-\mathrm{H})(\mu-\mathrm{CHTol})$ is proposed for this complex. The exact source of the oxo ligand in 2 and the fate of the second alkylidyne in 1 are unknown. However, based on reports in the literature, we speculate that the oxo ligand may be derived from a $\mathrm{CO}$ ligand by $\mathrm{C}-\mathrm{O}$ bond scission or from other possible sources $\left(\mathrm{O}_{2} \text { or } \mathrm{H}_{2} \mathrm{O}\right)^{8}$ in the solution and that the alkylidyne may be eliminated as a paraxylene molecule. ${ }^{9}$

The molecular structure of 2 was determined by a single-crystal X-ray diffraction study. The ORTEP diagram and the scheme used for labelling the atoms are shown in Fig. 1. The bond distances and angles are listed in Tables 1 and 2, respectively. The molecule consists of one tungsten atom and three osmium atoms which define a tetrahedral core associated with the expected 60 outer valence electrons. The tungsten atom is coordinated to a $\mathrm{Cp}$, a bridging oxo and a bridging alkylidene ligand, whereas each of the three basal osmium atoms is associated with three terminal CO ligands arranged in a pseudo-octahedral geometry.

The oxo ligand $\mathrm{O}(10)$ bridges the $\mathrm{W}-\mathrm{Os}(2)$ edge and the $\mathrm{W}-\mathrm{O}(10)-\mathrm{Os}(2)$ interaction is characterized by the short tungsten-oxygen bond distance $(\mathrm{W}-\mathrm{O}(1)=1.77 \AA)$, the comparatively long Os(2)-O(10) bond length $(2.13 \AA)$ and the small $\mathrm{W}-\mathrm{O}(10)-\mathrm{Os}(2)$ angle $\left(94.6^{\circ}\right)$. These data are compatible with the parameters for the typical
$\mathrm{W}=\mathrm{O} \rightarrow \mathrm{Os}$ bonding interaction as has been found previously in the related WOs $_{3}$ complexes. ${ }^{10}$ In addition, there is also a doubly bridging alkylidene ligand ( $\mu$-CHTol) which is associated with the second $\mathrm{W}-$ Os edge of the triangular face defined by the atoms $\mathrm{W}, \mathrm{Os}(1)$ and $\mathrm{Os}(2)$. The $\mathrm{W}-\mathrm{C}(22)$ distance $(2.08 \AA)$ is slightly shorter than the Os(1)-C(22) distance $(2.24 \AA)$ and the tolyl substituent is oriented toward the bridging oxo ligand. Finally, the structurally undetermined bridging hydride ligand is proposed to be associated with the third Os-Os edge of this $\mathrm{WOs}_{2}$ triangle. Consistent with our postulate, this metal-metal vector displays a relatively large Os(1)—Os(2) distance (2.997 $\AA$ ) and possesses two enlarged $\mathrm{Os}-\mathrm{Os}-\mathrm{CO}$ angles $\left(113-114^{\circ}\right)$ and two regular Os-Os- $-\mathrm{CO}$ angles $\left(89-94^{\circ}\right)$. The other two Os-Os distances within the molecule are slightly smaller, with Os(1)$\mathrm{Os}(3)=2.844(2)$ and $\mathrm{Os}(2)-\mathrm{Os}(3)=2.846(2) \AA$. After the position of the bridging hydride ligand is established, the formal electron counts for the W, Os(1), Os(2) and Os(3) atoms are calculated to be $17,18.5,19.5$ and $17 \mathrm{e}^{-}$, respectively.

The structure of 2 is different from those of the analogous hydrido-alkylidene complex 3 and the chloro-alkylidene complex 4 in terms of the location of the bridging hydride and the configuration of the bridging alkylidene ligand (Scheme 2). In complex 3 , the bridging hydride is located on the Os-Os edge eclipsed to the $\mathrm{W}-\mathrm{O}$ - edge which is associated with the alkylidene fragment; therefore, the metalmetal edges supporting the bridging hydride, oxo and alkylidene ligands are aligned in a zigzag

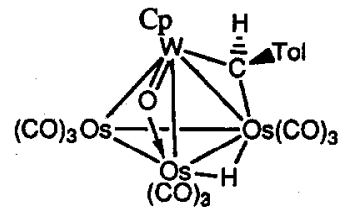

(2), anti

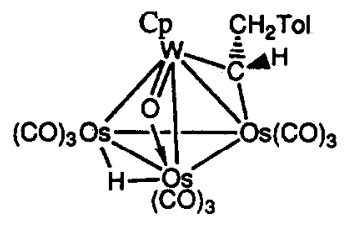

(3), syn

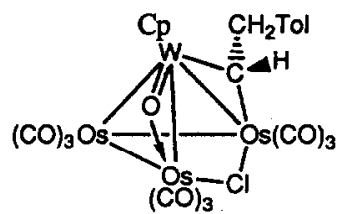

(4), syn

Scheme 2 . 


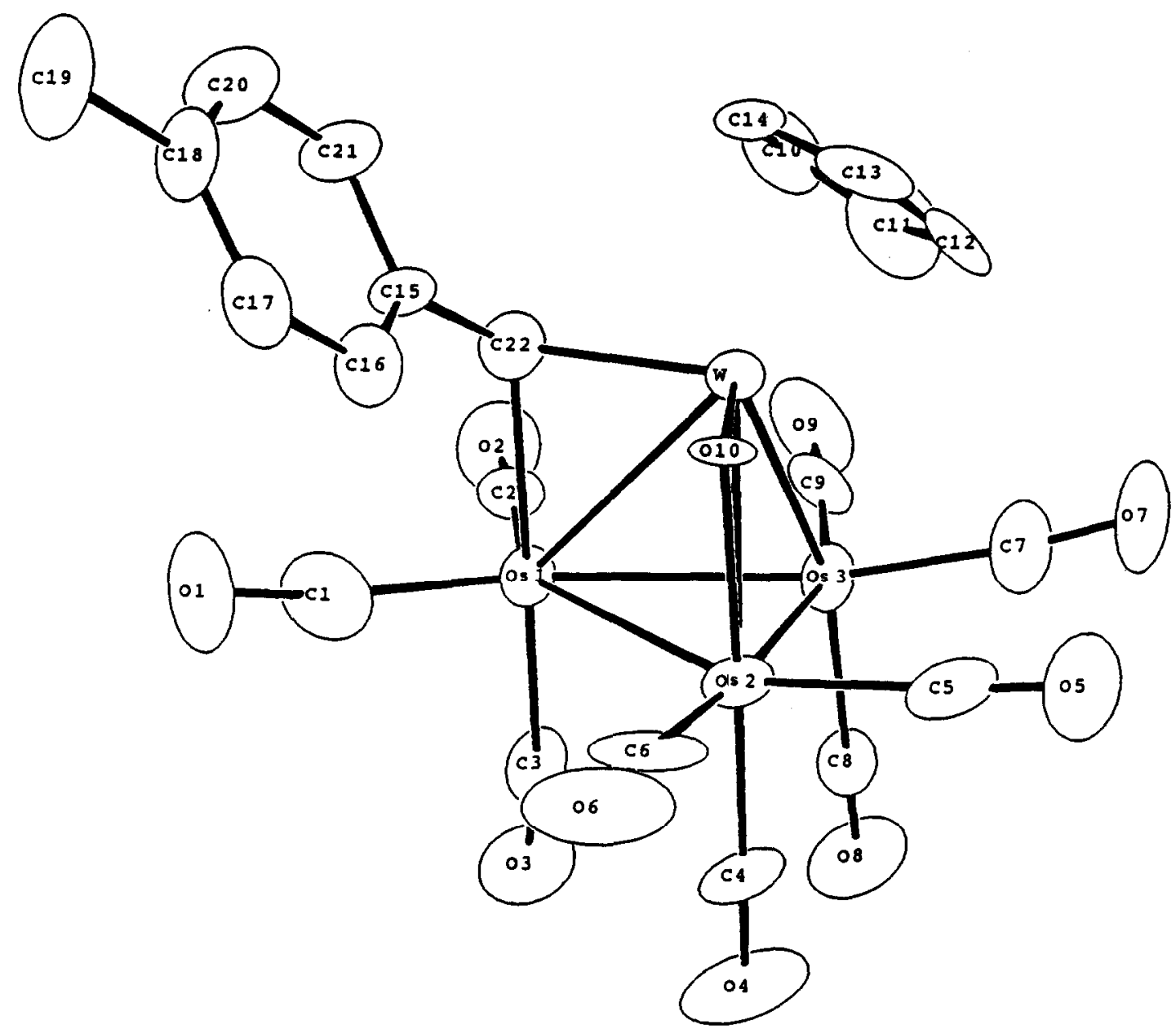

Fig. 1. The molecular structure of $\mathrm{CpWOs}_{3}(\mathrm{CO})_{9}(\mu-\mathrm{O})(\mu-\mathrm{H})(\mu-\mathrm{CHTol})(2)$ showing the atomic numbering scheme.

Table 1. Selectcd interatomic distances $(\AA)$ of complex 2 (ESADs in parentheses)

\begin{tabular}{llll}
\hline Os(1)-Os(2) & $2.977(2)$ & Os(1)-Os(3) & $2.844(2)$ \\
Os(2)-Os(3) & $2.846(2)$ & W-Os(1) & $2.857(2)$ \\
W-Os(2) & $2.874(2)$ & W-Os(3) & $2.629(2)$ \\
W-O(10) & $1.77(2)$ & Os(2)-O(10) & $2.13(?)$ \\
W-C(22) & $2.08(2)$ & Os(1)-C(22) & $2.24(2)$ \\
Os(1)-C(1) & $1.92(3)$ & Os(1)-C(2) & $1.95(3)$ \\
Os(1)-C(3) & $1.96(3)$ & Os(2)-C(4) & $1.86(3)$ \\
Os(2)-C(5) & $1.94(3)$ & Os(2)-C(6) & $1.68(4)$ \\
Os(3)-C(7) & $1.87(3)$ & Os(3)-C(8) & $1.95(3)$ \\
Os(3)-C(9) & $1.80(3)$ & C(1)-O(1) & $1.13(3)$ \\
C(2)-O(2) & $1.08(4)$ & C(3)-O(3) & $1.10(4)$ \\
C(4)-O(4) & $1.11(4)$ & C(5)-O(5) & $1.15(3)$ \\
C(6)-OC(6) & $1.30(5)$ & $\mathrm{C}(7)-O(7)$ & $1.17(3)$ \\
C(8)-O(8) & $1.08(4)$ & $\mathrm{C}(9)-O(9)$ & $1.19(4)$ \\
W-C(10) & $2.34(4)$ & W-C(11) & $2.39(4)$ \\
W-C(12) & $2.35(2)$ & W-C(13) & $2.37(3)$ \\
W-C(14) & $2.31(3)$ & C $(22)-C(15)$ & $1.53(3)$ \\
\hline
\end{tabular}

arrangement. In contrast, the bridging chloro ligand of complex 4 is located at a position similar to that of the bridging hydride in complex 2 ; therefore, the respective metal-metal edges are arranged in a triangular pattern. In addition, because the bridging chloro ligand is a three-electron-donor, the bond distance between the osmium atoms linked by chloro ligand is not in the range of a typical Os-OS single bond.

On the other hand, the $\alpha$-hydrogen of the alkylidene ligand in both complexes 3 and 4 is oriented toward the bridging oxo ligand; therefore, the configuration of the bridging alkylidene (denoted as $s y n$ ) is in contrast to that of complex 2 (denoted as anti). We propose that the formation of the anti configuration for complex 2 is due to its greater thermodynamic stability with respect to the unobserved syn configuration, and the latter is destabilized because of the unfavourable steric repulsion between the tolyl substituent and the $\mathrm{Cp}$ ligand. 
Table 2. Selected bond angles ( ) of complex 2 (ESADs in parentheses)

\begin{tabular}{lcll}
\hline W-Os(1)-Os(2) & $58.98(4)$ & W-Os(2)-Os(1) & $58.43(4)$ \\
Os(1)-W-Os(2) & $62.58(4)$ & W-Os(1)-Os(3) & $54.91(4)$ \\
W-Os(3)-Os(1) & $62.79(4)$ & Os(1)-W-Os(3) & $62.29(4)$ \\
W-Os(2)-Os(3) & $54.72(5)$ & W-Os(3)-Os(2) & $63.17(5)$ \\
Os(2)-W-Os(3) & $62.11(5)$ & Os(1)-Os(2)-Os(3) & $58.42(4)$ \\
Os(2)-Os(3)-Os(1) & $63.08(5)$ & Os(3)-Os(1)-Os(2) & $58.49(4)$ \\
Os(1)-C(1)-O(1) & $172(3)$ & Os(1)-C(2)-O(2) & $178(2)$ \\
Os(1)-C(3)-O(3) & $172(3)$ & Os(2)-C(4)-O(4) & $177(4)$ \\
Os(2)-C(5)-O(5) & $176(3)$ & Os(2)-C(6)-O(6) & $169(3)$ \\
Os(3)-C(7)-O(7) & $174(3)$ & Os(3)-C(8)-O(8) & $175(4)$ \\
Os(3)-C(9)-O(9) & $178(2)$ & Os(1)-C(22)-W & $82.7(8)$ \\
W-Os(1)-C(22) & $46.3(5)$ & Os(1)-W-C(22) & $51.1(6)$ \\
Os(2)-O(10)-W & $94.6(7)$ & Os(2)-W-O(10) & $47.5(5)$ \\
W-Os(2)-O(10) & $37.9(5)$ & W-C(22)-C $(15)$ & $119(2)$ \\
Os(1)-C(22)-C(15) & $123(2)$ & Os(1)-Os(2)-C(4) & $94.4(9)$ \\
Os(1)-Os(2)-C(6) & $113(1)$ & Os(2)-Os(1)-C(1) & $114(1)$ \\
Os(2)-Os $(1)-C(3)$ & $89(1)$ & & \\
\hline
\end{tabular}

\section{EXPERIMENTAL}

IR spectra were recorded using a Perkin-Elmer 580 spectrometer calibrated using the absorption of cyclohexane at $2138.5 \mathrm{~cm}^{-1}$ and the absorption of polystyrene film at $1944.5 \mathrm{~cm}^{-1}$. Both ${ }^{1} \mathrm{H}$ and ${ }^{13} \mathrm{C}$ NMR spectra were recorded using a Bruker AM400 instrument. Mass spectra were obtained on a JEOL-HX110 instrument operating in electron impact, field desorption or fast atom bombardment modes. All reactions were performed under a nitrogen atmosphere using deoxygenated solvents dried with an appropriate reagent. The progress of reactions was monitored by analytical TLC ( $5735 \mathrm{Kie}-$ selgel $60 \mathrm{~F}_{254}$, E. Merck) and the products were separated on the commercially available preparative TLC plates (Kieselgel $60 \mathrm{~F}_{254}$, E. Merck). The mixed-metal complexes $\mathrm{CpWOs}_{3}(\mathrm{CO})_{9}\left(\mu_{3^{-}}\right.$ CTol $)_{2}(\mu-\mathrm{H})(1)$ were prepared according to the literature method. ${ }^{4}$

\section{Preparation of $\quad \mathrm{CpWOs}_{3}(\mathrm{CO})_{9}(\mu-\mathrm{O})(\mu-\mathrm{H})(\mu-$ CHTol) (2)}

A xylene solution $\left(45 \mathrm{~cm}^{3}\right)$ of $\mathrm{CpWO}_{3}(\mathrm{CO})_{9}\left(\mu_{3^{-}}\right.$ $\mathrm{CTol})_{2}(\mu-\mathrm{H})$ (1) (56 $\left.\mathrm{mg}, 0.043 \mathrm{mmol}\right)$ was heated at reflux under $1 \mathrm{~atm}$ of hydrogen. After refluxing for $6 \mathrm{~h}$, the solvent was evaporated in vacuo and the residue was separated on a preparative TLC plate (hexane-dichloromethane, $3: 2$ ), giving the alkylidene complex $2(6 \mathrm{mg}, 0.005 \mathrm{mmol}, 12 \%)$ as redorange crystals after recrystallization from dichloromethane-methanol. In addition, some starting materials ( $10 \mathrm{mg}, 0.008 \mathrm{mmol}, 18 \%)$ were also recovered from the residue of the reaction mixture.
Spectroscopic data for complex 2. MS (EI, ${ }^{192} \mathrm{Os,}$ $\left.{ }^{184} \mathrm{~W}\right), m / z 1198\left(\mathrm{M}^{+}\right)$; IR( $\left(\mathrm{C}_{6} \mathrm{H}_{12}\right): v(\mathrm{CO}), 2090(\mathrm{~s})$, 2065(vs), 2028(vs), 2020(vs), 2014(s), 2007(m), 1991(w), 1958(w), 1940(m) $\mathrm{cm}^{-1} ;{ }^{1} \mathrm{H}$ NMR (400 $\left.\mathrm{MHz}, \mathrm{CDCl}_{3}, 294 \mathrm{~K}\right): \delta 7.05-6.45(\mathrm{~m}, 4 \mathrm{H}), 5.94(\mathrm{~s}$, $5 \mathrm{H}), 5.52(\mathrm{~s}, 1 \mathrm{H}), 2.39(\mathrm{~s}, 3 \mathrm{H}),-18.05(\mathrm{~s}, 1 \mathrm{H}) ;{ }^{13} \mathrm{C}-$ $\{\mathrm{H}\}$ NMR $\left(100.4 \mathrm{MHz}, \mathrm{CDCl}_{3}, 213 \mathrm{~K}\right): \mathrm{Os}-\mathrm{CO}$, $\delta$ 194.5, 184.4, 181.4, 180.9, 176.4, 173.2, 169.9, $169.7,169.1$.

\section{Structural determination of complex $\mathbf{2}$}

Crystals suitable for diffraction analysis were obtained from a dichloromethane-methanol solution. A crystal was mounted on a glass fibre. Diffraction measurements were carried out on a Nonius CAD-4 fully automated four-circle diffractometer. The unit cell was determined and refined using setting angles of 25 randomly selected reflections, with $2 \theta$ angles in the range of $2.5-50^{\circ}$, obtained by using the CAD-4 automatic search, centre, index and least-squares routines. All data reduction and structure refinement were performed using the NRCC-SDP-VAX packages. The structure was solved by the Patterson method and refined by least-squares; all non-hydrogen atoms were refined with anisotropic thermal parameters. The data collection parameters are summarized in Table 3. Tables of atomic coordinates, anisotropic thermal parameters, structure factor amplitudes, and non-essential bond distance and angle parameters have been deposited as supplementary data and are available from the authors (S.M.P.). 
Table 3. Experimental data for the X-ray diffraction study of complex 2

(A) Crystal data

$\begin{array}{ll}a(\AA) & 9.763(5) \\ b(\AA) & 10.759(4) \\ c(\AA) & 13.336(3) \\ \alpha\left({ }^{\circ}\right) & 88.00(3) \\ \beta\left({ }^{\circ}\right) & 108.56(3) \\ \gamma\left(^{\circ}\right) & 100.44(3) \\ F(000) & 1056 \\ \text { Tcmpcraturc }(\mathrm{K}) & 297 \\ \text { Crystal system } & \text { Triclinic } \\ \text { Space group } & P \overline{1} \\ Z & 2 \\ \text { Formula } & \mathrm{C}_{22} \mathrm{H}_{14} \mathrm{O}_{10} \mathrm{Os}_{3} \mathrm{~W}_{1} \\ V\left(\AA^{3}\right) & 1305.6(9) \\ \text { Molecular weight } & 1192.8 \\ \text { Density }(\text { calc. })\left(\mathrm{g} \mathrm{cm}^{-3}\right) & 3.034\end{array}$

(B) Data collection, reduction, solution and refinement

Data collection instrument

Radiation (monochromated in incident beam)

Scan method

Scan range

Scan speed

Crystal size (mm)

Linear absorption coefficient $\left(\mathrm{mm}^{-1}\right)$

Transmission factors: $\max$, min.

Number of unique data, total with $I>3 \sigma(I)$

Number of atoms and parameters refined

Largest and mean $\Delta / \sigma$

$R ; R_{\mathrm{w}}{ }^{a}(\%)$

G.O.F.

Residual electron density $\left(\mathrm{e} \AA^{-3}\right.$ ): $\max . / \min$.

\author{
Nonius CAD-4 \\ $\operatorname{Mo}-K_{\alpha}(\lambda=0.71073 \AA)$ \\ $2 \theta-\theta$ scan mode \\ $0.65+0.35 \tan \theta$ \\ Variable; $1.10-8.24^{\circ} / \mathrm{min}$ \\ $0.25 \times 0.40 \times 0.40$ \\ 19.10 \\ $0.99,0.55$ \\ 4574,3463 \\ 36,326 \\ $0.228,0.001$ \\ $5.7 ; 5.8$ \\ 3.71 \\ $4.43 /-2.88$
}

\footnotetext{
${ }^{a} \mathrm{~W}^{-1}=\sigma^{2}(F)$.

${ }^{b} \mathrm{~S}=\left[\Sigma \mathrm{w}\left|F_{\mathrm{o}}-F_{\mathrm{c}}\right|^{2} /\left(N_{\mathrm{o}}-N_{\mathrm{v}}\right)\right]^{1 / 2}\left(N_{\mathrm{o}}=\right.$ number of observations; $N_{\mathrm{v}}=$ number
} of variables).

\section{REFERENCES}

1. D. A. Roberts and G. L. Geoffroy, in Comprehensive Organometallic Chemistry (Edited by $\mathrm{G}$. Wilkinson, F. G. A. Stone and E. W. Abel), Vol. 6, Ch. 40. Pergamon Press, Oxford (1982).

2. (a) F. G. A. Stone, in Inorganic Chemistry: Toward the 21st Century (Edited by M. H. Chisholm), ACS Symp. Ser. No. 211, p. 383. American Chemical Society, Washington, D.C. (1983) ; (b) S. J. Davies, J. A. K. Howard, R. J. Musgrove and F. G. A. Stone, Angew. Chem. Int. Edn Engl. 1989, 28, 624 and refs cited therein.

3. (a) E. L. Muetterties and J. Stein, Chem. Rev. 1979, 79, 479 ; (b) L. R. Beanan and J. B. Keister, Organometallics 1985, 4, 1713.

4. (a) J. T. Park, J. R. Shapley, C. Bueno, J. W. Ziller and M. R. Churchill, Organometallics 1988, 7, 2307 ; (b) J. T. Park, J. R. Shapley, M. R. Churchill and C. Bueno, J. Am. Chem. Soc. 1983, 105, 6182.

5. M. R. Churchill and Y. J. Li, J. Organomet. Chem. 1985, 291, 61.

6. Y. Chi, J. R. Shapley, J. W. Ziller and M. R. Churchill, Organometallics 1987, 6, 301.

7. Y. Chi, L.-S. Hwang, G.-H. Lee and S.-M. Peng, J. Chem. Soc., Chem. Commun. 1988, 1456.

8. M. R. Churchill, C. Bueno, J. T. Park and J. R. Shapley, Inorg. Chem. 1984, 23, 1017.

9. (a) J. B. Keister, J. Chem. Soc., Chem. Commun. 1979, 214 ; (b) G. Fachinetti, R. Lazzaroni and S. Pucci, Angew. Chem. Int. Edn Engl. 1981, 20, 1063; (c) J. B. Keister, M. W. Payne and M. J. Muscatella, Organometallics 1983, 2, 219.

10. M. R. Churchill and Y. J. Li, J. Organomet. Chem. $1985,294,367$. 